\title{
The impact of physical activity and an additional behavioural risk factor on cardiovascular disease, cancer and all-cause mortality: a systematic review
}

\author{
Jason Lacombe ${ }^{1 *}$ (D, Miranda E. G. Armstrong ${ }^{2}$, F. Lucy Wright ${ }^{3}$ and Charlie Foster ${ }^{2}$
}

\begin{abstract}
Background: Regular physical activity improves overall health, and has the capacity to reduce risk of chronic diseases and death. However, better understanding of the relationship between multiple lifestyle risk behaviours and disease outcomes is pertinent for prioritising public health messaging. The aim of this systematic review is to examine the association between physical inactivity in combination with additional lifestyle risk behaviours (smoking, alcohol, diet, or sedentary behaviour) for cardiovascular disease, cancer, and all-cause mortality.

Methods: We searched Ovid Medline, EMBASE, and the Cochrane Register from 1 January 2010 to 12 December 2017, for longitudinal observational studies of adults (18+ years) in the general population with a publication date of 2010 onwards and no language restriction. Main exposure variables had to include a physical activity measure plus at least one other lifestyle risk factor. In total, 25,639 studies were identified. Titles, abstracts and full-text articles of potentially relevant papers were screened for eligibility. Data was extracted and quality assessment was completed using a modified Newcastle-Ottawa Scale (NOS).

Results: Across the 25 eligible studies, those participants who reported being physically active combined with achieving other health behaviour goals compared to those who were categorised as physically inactive and did not achieve other positive lifestyle goals, were at least half as likely to experience an incident cardiovascular disease (CVD) event, die from CVD, or die from any cause. These findings were consistent across participant age, sex, and study length of follow-up, and even after excluding lower quality studies. We also observed a similar trend among the few studies which were restricted to cancer outcomes. Most studies did not consider epidemiological challenges that may bias findings, such as residual confounding, reverse causality by pre-existing disease, and measurement error from self-report data.
\end{abstract}

Conclusions: High levels of physical activity in combination with other positive lifestyle choices is associated with better health outcomes. Applying new approaches to studying the complex relationships between multiple behavioural risk factors, including physical activity, should be a priority.

\footnotetext{
* Correspondence: jason.lacombe@hertford.ox.ac.uk

${ }^{1}$ Cancer Epidemiology Unit, University of Oxford, Oxford, UK

Full list of author information is available at the end of the article
}

(c) The Author(s). 2019 Open Access This article is distributed under the terms of the Creative Commons Attribution 4.0 International License (http://creativecommons.org/licenses/by/4.0/) which permits unrestricted use, distribution, and reproduction in any medium, provided you give appropriate credit to the original author(s) and the source, provide a link to the Creative Commons license, and indicate if changes were made. The Creative Commons Public Domain Dedication waiver (http://creativecommons.org/publicdomain/zero/1.0/) applies to the data made available in this article, unless otherwise stated. 


\section{Background}

An individual's lifestyle behaviours greatly influence their likelihood of developing and dying of many diseases. In middle to high income countries, physical inactivity, unhealthy eating, smoking, and alcohol consumption, are estimated to contribute to $29 \%$ of disease and disabilityadjusted life-years lost [1]. According to the World Health Organisation Global Health Risk report, high blood pressure, tobacco use, high blood glucose, physical inactivity, overweight and obesity, high cholesterol, unsafe sex, alcohol use, and low fruit and vegetable intake are the leading risk factors for death in high income countries. Although there are other lifestyle risk factors that have been associated with noncommunicable disease development and death, this review focuses on the most common risk factors which have the biggest effect on disease development and death [2]. These multiple behaviours are also associated with many disease comorbidities, such as, being overweight or obese, and having high levels of cholesterol, which result in an additional 15\% elevated risk, and taken together represent a significant public health problem [1].

The independent effects of each of these behaviours on health outcomes are well-established [3-5]. Therefore, it may seem reasonable to presume that if an individual engages in more than one of these unhealthy behaviours, the potential synergistic interaction amongst them should result in poorer health outcomes. However, the research is limited in assessing the co-distribution of these risk factors, and how the patterns of these risk factors have been evolving over time. Historically, the assessment of multiple behavioural risk factors on health outcomes has primarily used co-occurrence methodologies, which evaluate concurrent but independent engagement in two or more behaviours [6]. In the United Kingdom (UK), $70 \%$ of the adult population is estimated to engage in 2 or more of these unhealthy behaviours [1].

Past research has shown that behavioural risk factors are often tackled in policy and clinical contexts as separate issues, to be explored and managed by unique teams and resources [1]. Despite national guidelines and recommendations from the Department of Health [7], the National Institute for Health and Care Excellence [8] and the Royal College of General Practitioners, choosing physical activity as a clinical priority, and its promotion remains sporadic and undervalued compared to other risk behaviours [9]. Indeed, the impact of screening programmes for the primary prevention of cardiovascular disease, including modification of behavioural risk factors, appears limited [10]. However, until we can understand the independent and also synergistic impacts of changing other risk behaviours with physical inactivity the choice of which one to address will remain uninformed. If this were determined, it would help to inform clinicians, researchers, and policy decision makers to better explore multiple lifestyle risks with/for their patients, by understanding their impact on multiple comorbidities and poor health outcomes.

Here, we aim to systematically evaluate how the association between physical activity in combination with additional lifestyle risk behaviours impacts cardiovascular disease, cancer, and all-cause mortality, and the methods that have been used in previous research to examine the co-distribution of multiple behaviours in adults. Our review is the first global systematic review of adult cohort studies that has examined the associations between physical activity in combination with smoking, alcohol, diet and sedentary behaviour on all-cause mortality, and incident cases or mortality from cardiovascular disease or cancer.

\section{Methods}

\section{Search strategy and eligibility criteria}

We searched Ovid MEDLINE (from 1946), EMBASE (from 1988) and the Cochrane Central Register between 1 January 2010 and 12 December 2017, with no language restrictions, for studies in humans to identify research papers estimating the relationship between physical activity as an exposure variable in combination with one or more other health risk behaviours (smoking, alcohol, diet, or sedentary behaviour), on all-cause mortality, and incident cases or mortality from cardiovascular disease or cancer [7] (Additional file 3). Across the studies, participants were classified as active if those participants met the weekly physical activity guidelines in the country that the study took place. Any participant not meeting the physical activity guidelines were classified as inactive or categorised into a less healthy category. We only focused on the extreme groups (most active group + healthiest profile compared to least active + least healthy profile) when co-occurrence methodologies were used. Our search consisted of terms related to physical activity, smoking, diet, sedentary behaviour, and alcohol consumption, and combined these terms with cardiovascular disease, cancers, mortality and related terms. We also searched reference lists of relevant articles, and of previous reviews. For a detailed list of all search terms used in each database, refer to Additional file 1. The protocol for this systematic review has been published to the PROSPERO register (Reference ID: CRD42017050378 [11]) and the abstract has been presented at the International Society of Behavioral Nutrition and Physical Activity conference.

We included cohort studies of adults (18+ years) from the general population with a publication date of 2010 onwards if they investigated associations between physical activity and at least one additional risk factor 
(smoking, alcohol, diet, or sedentary behaviour). We only included studies that reported the exclusion of participants with prevalent disease at baseline. Additionally, a start date of 2010 was chosen to align with the date that the World Health Organisation released the most recent global physical activity guidelines [12], and studies with a minimum of 8 years of follow-up were included. We excluded cohorts which were not free-living populations (i.e., hospital patient studies), fitness studies, nutritional supplement, and studies which used a certain type of beverage as a measure of nutrition (i.e., green tea, protein shake). We excluded populations in which studies were restricted to focus on an occupational group, and thus would not be representative of the larger free-living population (i.e., nurse's, factory workers, students enrolled in a psychology course). We also excluded letters, comments, reviews, meta-analysis, randomised control trials, ecological studies, and animal studies.

\section{Data extraction and quality assessment}

Data extraction was conducted with a standard data collection form describing the characteristics of each study and the main results (Additional file 1). We recorded the following characteristics in the identified studies: author names, name of the paper, cohort name, country, publication year, age at entry, sex, sample size of cohort, confirmation of eligibility criteria $(y / n)$, method used to group lifestyle behaviours, outcome(s), duration of follow-up, method of assessment of physical activity, ascertainment of outcomes, adjustment variables in the multivariate model, regression dilution correction applied $(y / n)$, how was handling of missing data completed, and overall main finding. We also extracted information on whether the study had considered bias, residual confounding, measurement error, and regression dilution. We used hazard ratios or relative risks as a measure of association. The primary exposure variable was physical activity and, as a minimum, one other lifestyle risk factor. Outcomes of interest in this review were all-cause mortality, cardiovascular incidence/mortality, and cancer incidence/mortality.

We assessed study quality using a modified NewcastleOttawa Scale (NOS) for cohort studies [13]. The NOS assesses the quality of nonrandomised studies. A point system has been developed in which a study is judged on, the selection of the study groups, the comparability of the groups, and the ascertainment of either the exposure or outcome of interest for cohort studies. The NOS is recommended by the Cochrane Collaboration as an assessment tool for cohort studies to assess risk of bias. The content validity of the NOS has been established based on a critical examination by several experts. Using NOS for cohort studies, the maximum score a study can receive is 9 points. For this review, we then added additional criteria, to assess the strength of the physical activity measure that was used in more detail, and to explore the control variables that studies used. Using the modified scale, a study could be awarded a maximum of 10 points. Relating to the question on ascertainment of exposure, the question was modified, and studies were given a point if they used either structured interview, or a validated self-report measure. Studies were awarded an additional point (bringing the total up to 10) if they controlled for age, sex, or a measure of socio-economic status/education.

\section{Data synthesis}

Overall, studies included in this review were too heterogeneous in terms of participant characteristics, intervention design, and outcome measures to allow for a detailed meta-analysis, thus data was synthesised descriptively. Some additional analysis to examine the highest-quality studies in more detail was conducted using the statistical program $\mathrm{R}$ (version 3.3.3) and a forest plot was created.

To be included in the preliminary analysis (Table 1), all studies had to have at minimum 8 years of follow-up and a measure of physical activity with an additional exposure variable. Studies also needed to score 8 points or higher on the modified NOS. To take this further, we did more detailed analysis on studies which met these criteria, and additionally used a validated self-report physical activity measure or objective measure. We present all the results in one direction examining the healthiest profile against the least healthy profile. As a result, when necessary the inverse risk ratio has been calculated. In general for all results, the risk ratios are presented and a forest plot was created to visualise the risk relationship between lifestyle behaviour, and disease/death outcomes with the healthiest lifestyle group as the reference compared to the least healthy lifestyle group. We also plotted the $95 \%$ Confidence Intervals for each study of interest. For studies which presented risk associations and confidence intervals where the least healthy group was used as the reference, we computed and plotted the inverse risk and confidence intervals.

\section{Results}

\section{Literature search}

From an initial 25,639 studies retrieved, and following removal of duplicates $(n=7621)$, we screened 18,018 titles. Exclusion by title for all returned results (JL), and a $10 \%$ double review of titles was completed by 2 independent assessors (JL and MA). This resulted in 4339 abstracts to be reviewed (JL) and all abstracts were completed (JL and CF) by two independent assessors. This left 181 full-text articles, which were read in-detail (JL), 


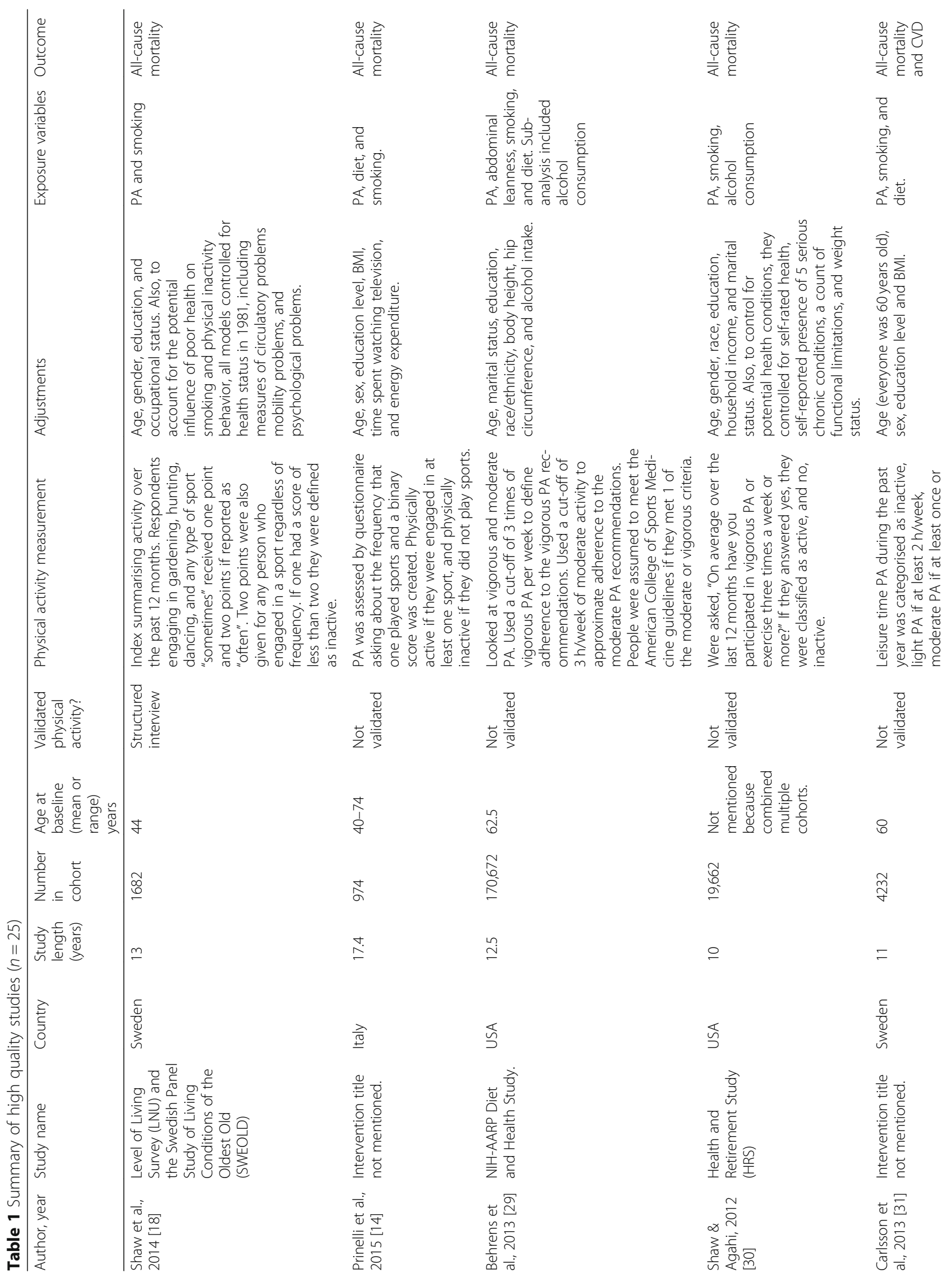




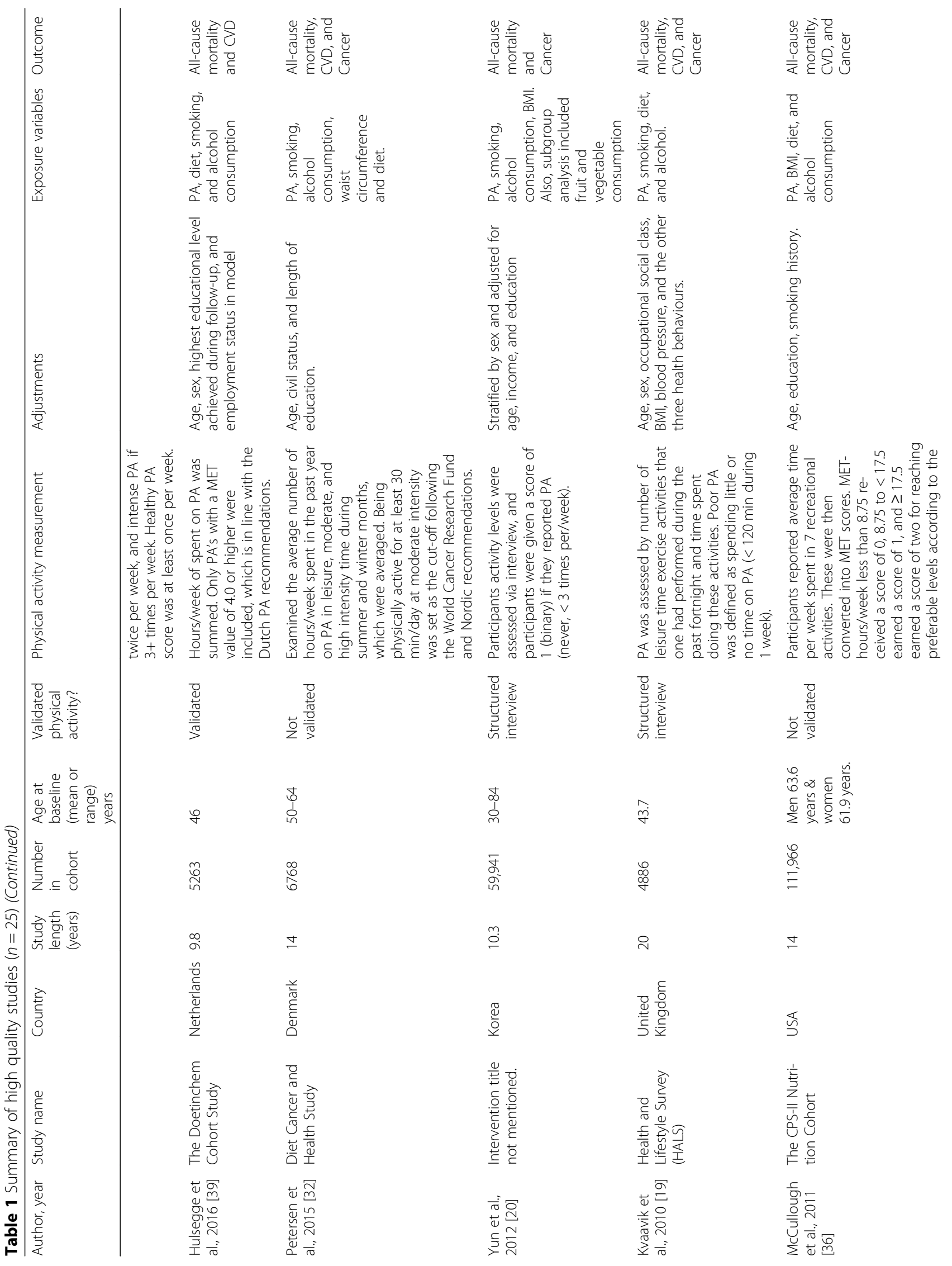




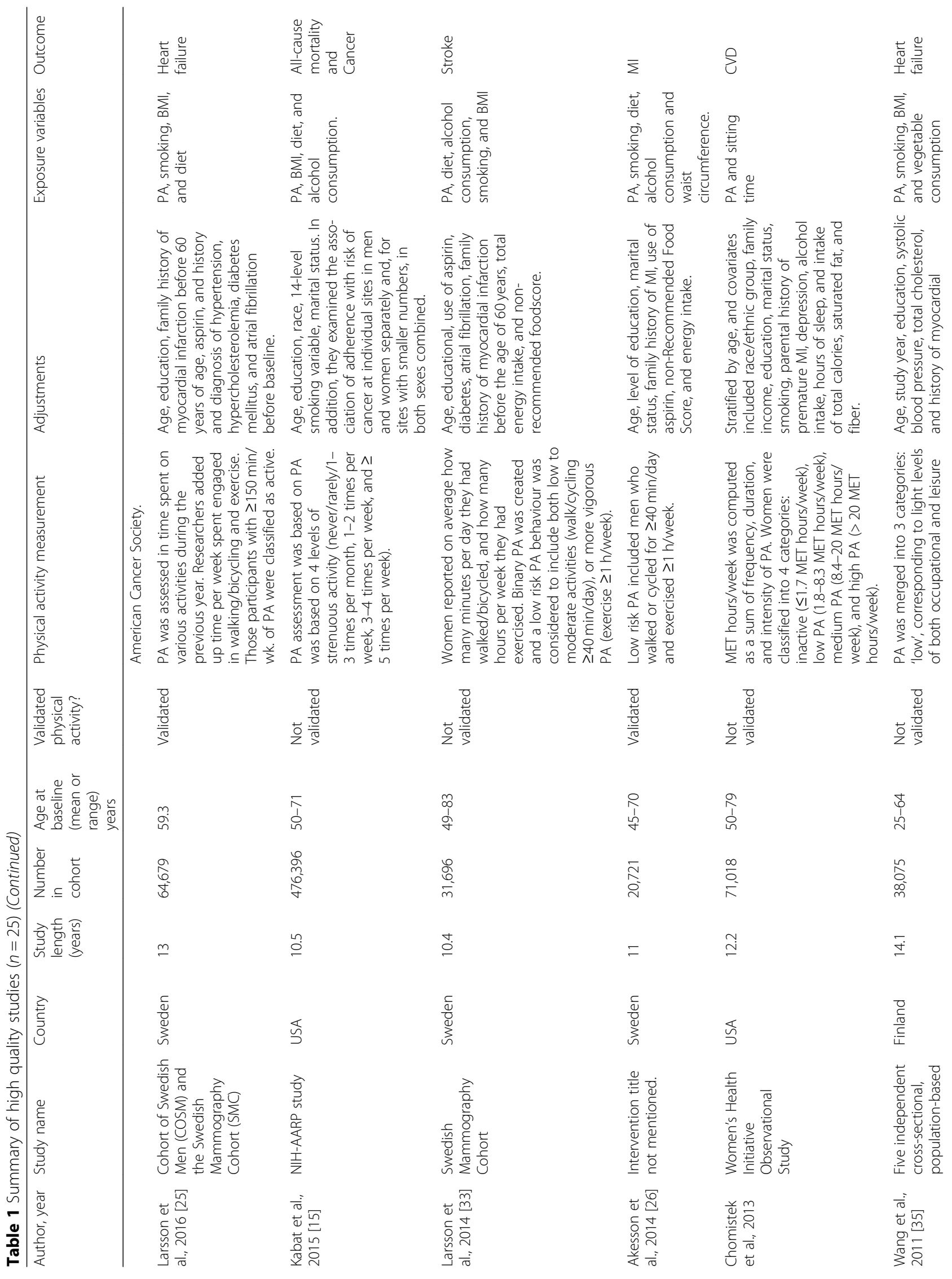




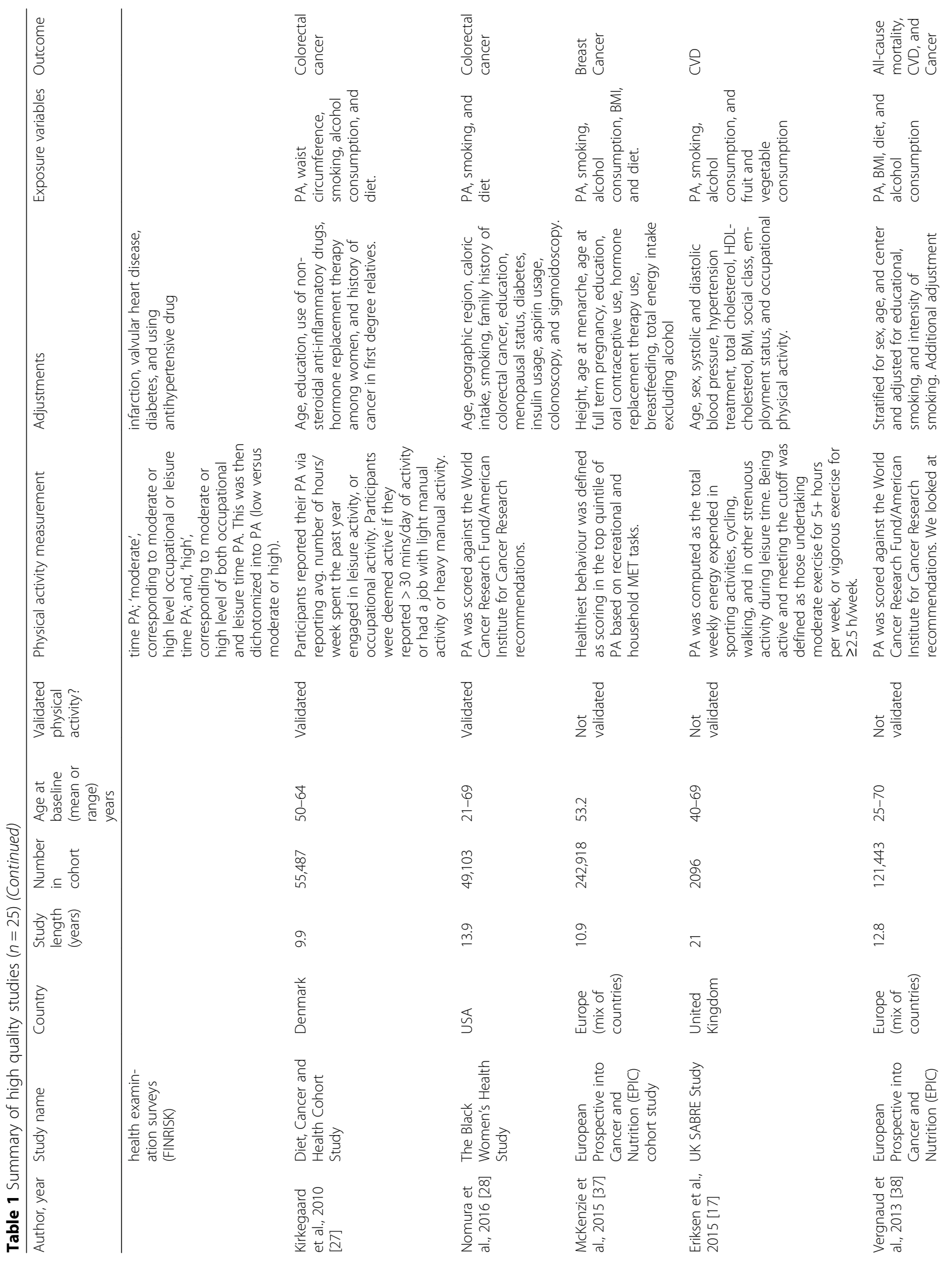


Lacombe et al. BMC Public Health

(2019) 19:900

Page 8 of 16

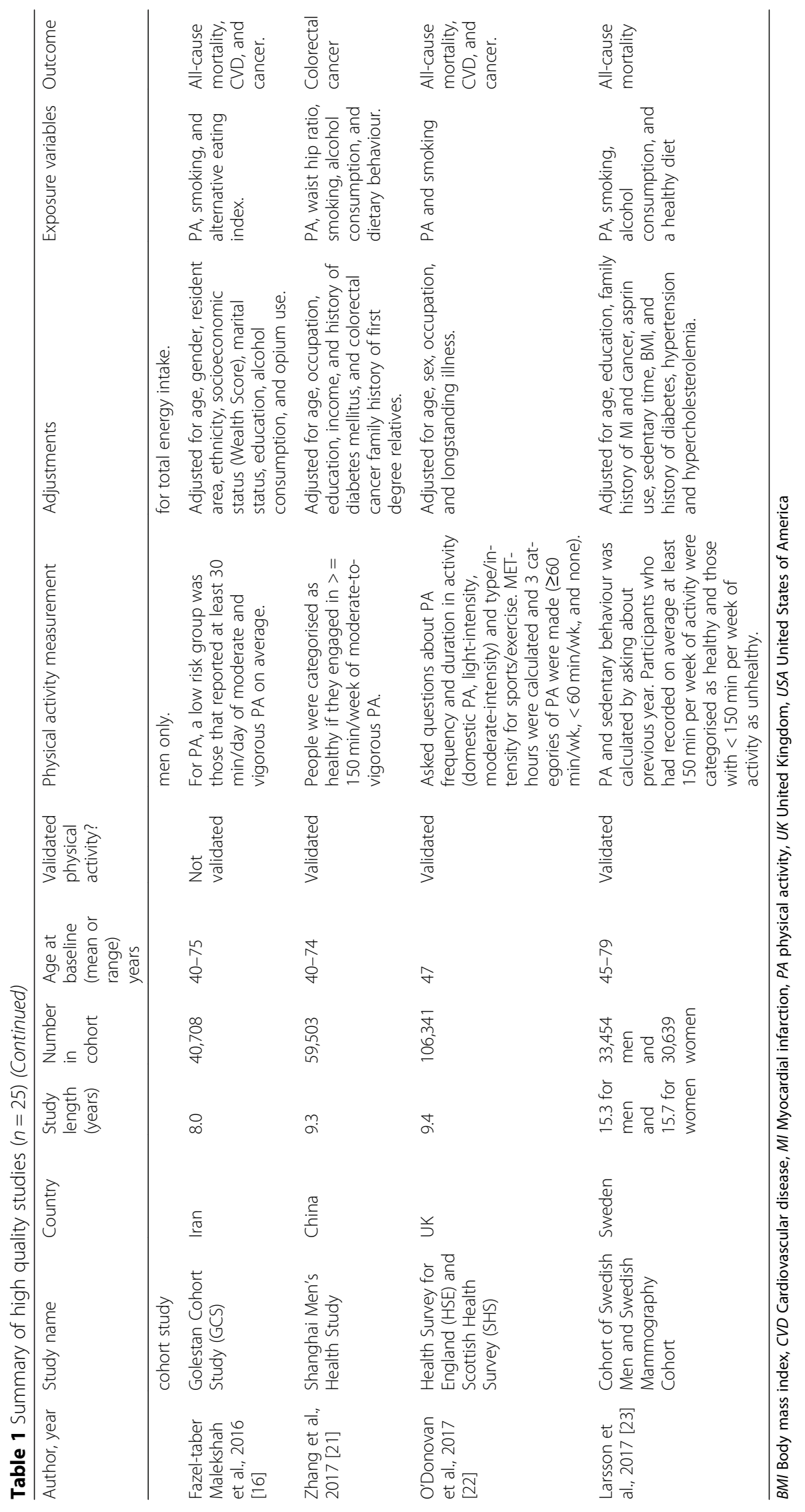


and 84 of these were then excluded because they did not meet inclusion criteria. Data extraction including the characteristics of the samples, methods, and main results was completed for the remaining 97 eligible studies (JL). From data extraction, 39 studies did not meet our criteria, and were excluded. A total of 58 studies were included for the final step, which comprised quality assessment completed independently by 2 assessors (JL \& FLW). For the final analysis, we included only studies which scored at least 8 points or higher out of 10 $(n=25)$. A Preferred Reporting Items for Systematic Reviews and Meta-Analyses (PRISMA) flow diagram is presented showing study inclusion decisions (Fig. 1) and a PRISMA checklist is presented in the Additional file 2.

\section{Included studies and measures}

Table 1 summarizes the characteristics of the 25 studies included. Studies were conducted in the USA $(n=6)$, Sweden $(n=6)$, multiple European countries $(n=2)$,

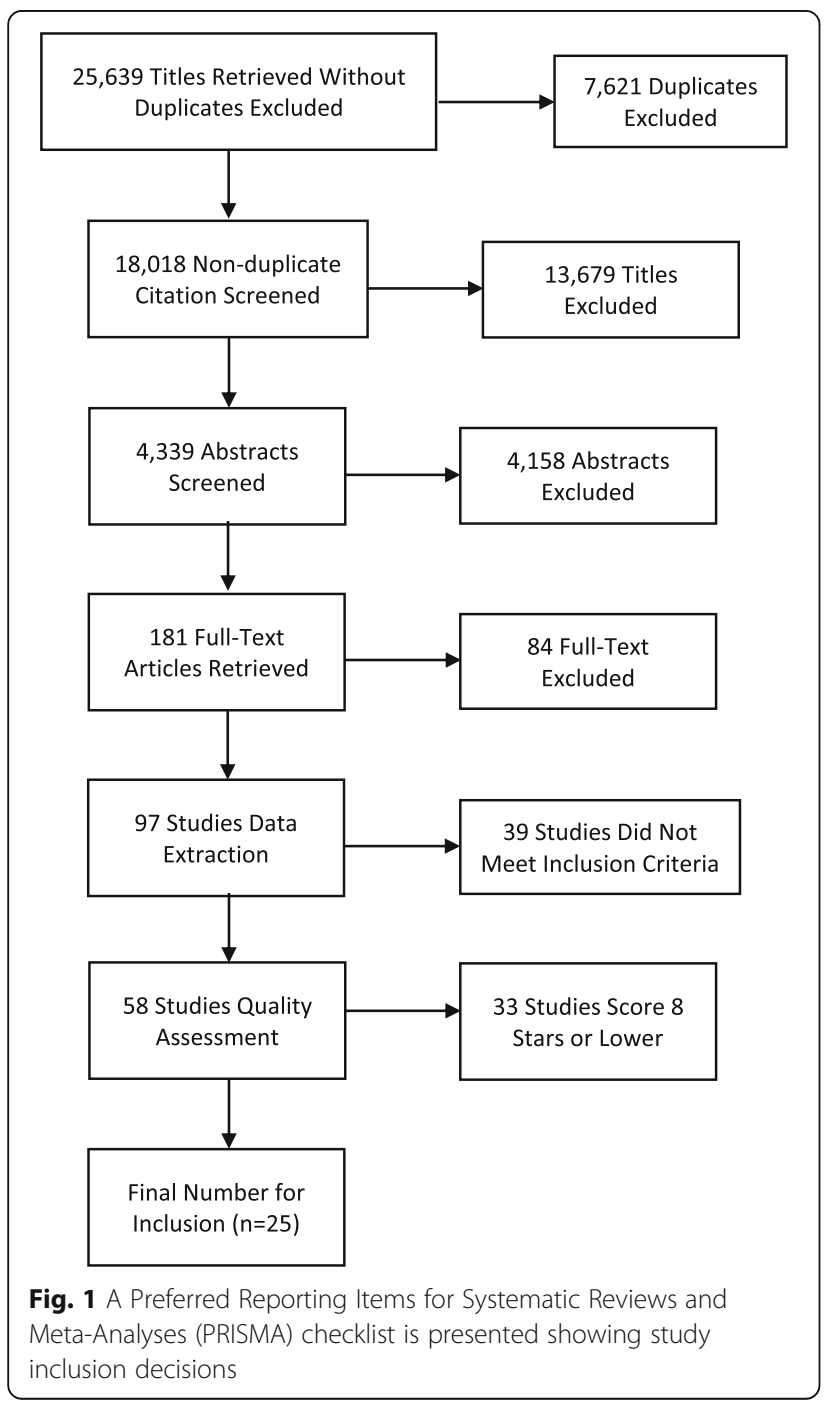

Denmark $(n=2)$, United Kingdom $(n=3)$, Italy $(n=1)$, Netherlands $(n=1)$, Korea $(n=1)$, China $(n=1)$, Iran $(n=1)$, and Finland $(n=1)$. The number of participants in each study ranged from 974 [14] to 476,396 [14]. The minimum study length of follow-up was 8.1 years [15], and the maximum was 21 years [16]. In total, 3 studies used a structured interview to assess physical activity behaviour [17-19], 8 used a validated self-report questionnaire [19-26], and 14 did not use a validated questionnaire [14-16, 27-37]. No study included an objective measure of physical activity (i.e., accelerometry or pedometers).

\section{Outcomes}

\section{All-cause mortality}

There was strong evidence that more physical activity and choosing better lifestyle behaviours led to longer survival in all 15 high quality studies examining allcause mortality. However, the level of risk varied across different combinations of behavioural patterns. All studies found that a high adherence to positive factors including higher levels of physical activity, not smoking, eating healthy, and limited sedentary behaviour and alcohol consumption were strongly associated with reduced risk of all-cause mortality after long-term followup, and that this association was even stronger when these positive behaviours were combined $[14,17-19$, 21-23, 27-31, 35, 37].

For example, Kvaaik and Colleagues (2010) found that after 20-years of follow-up, those in the healthiest category for all 4 lifestyle behaviours versus those in the least healthy category of lifestyle behaviours had a total mortality risk of $0.29(\mathrm{CI}=0.19-0.43)$ [18]. Similarly, Prinelli and Colleagues (2015) followed subjects for an average of 17.4 years, and found that those with 1,2 , or 3 healthy behaviours had a significantly reduced risk of death of, 39, 56, and 73\% respectively [14]. Petersen and Colleagues (2015) and McCullough and Colleagues (2011) both followed men and women for 14 years on average and found that every additional health recommendation adhered to, had a greater protective effect against mortality [31, 35]. Comparing lifestyle scores, Fazel-taber Malekshah and colleagues (2016) reported on observations from 40,708 participants, adults in the most healthy group had a significantly reduced risk of morality $(\mathrm{RR}=0.68 ; \mathrm{CI}=0.54-0.86)$ compared to those in the least healthy group [15].

When examining the associations by different subgroups, McCullough and Colleagues (2011) limited their study to only non-smokers to explore in more detail the impact that following other prevention guidelines besides tobacco avoidance has on a cohort [35]. When examining all-cause mortality outcomes by sex, Larsson and Colleagues (2017) found that those with all four 
positive health behaviours compared to 0 had a reduced risk for men $(R R=0.47 ; C I=0.44-0.51)$ and women $(\mathrm{RR}=0.39 ; \mathrm{CI}=0.35-0.44)$ [22]. Similarly, Yun and colleagues (2012) found men and women with 4 healthy lifestyle factor points including high levels of physical activity compared to no healthy lifestyle factor points and no physical activity reported had a $0.50(0.23-1.08)$ [19]. Behrens and Colleagues (2013) included a measure of adiposity in their lifestyle score and found that these results held, even with an additional measure [28]. Physical activity significantly reduced risk of mortality independently $(R R=0.86 ; C I=0.84-0.89)$ with the larger the number of positive behaviours adhered to, the lower the risk, estimating that $33 \%$ of deaths were prevented if subjects adhered to all positive health behaviours. Examining the dual-associations between physical activity duration and history of smoking, O'Donovan and colleagues (2017) found those who exercised for over $60 \mathrm{~min} /$ week and were never smokers had a significantly reduced mortality risk compared to those who did no exercise and were current smokers, $(\mathrm{RR}=0.29 ; \mathrm{CI}=0.24-0.36)$ [21].

\section{Cardiovascular disease}

A total of 14 high quality studies included a CVD outcome. This included 10 which examined CVD broadly $[15,16,18,21,30,31,33,35,37,38], 1$ stroke incidence [32], 1 myocardial infarction [25], and 2 heart failure $[24,34]$. Similar to the all-cause mortality findings, there was evidence that engaging in regular physical activity, and additional healthy behaviours was associated with a reduced risk for developing and dying of cardiovascular outcomes, and these finding were consistent across gender, age, and populations sampled. After 21 years of follow-up in a sample of 2096 participants, Eriksen and Colleagues (2015) found that the population attributable fraction for Coronary Heart Disease (CHD) and CVD amongst both Europeans $(n=1090)$ and South Asians ( $n=1006$ ) was $43 \%$ for CHD and $28 \%$ for CVD in Europeans and 63\% for CHD and 51\% for CVD in South Asians who did not have any of the four healthy behaviours surveyed at baseline [16]. Kvaanik and others (2010) looked at the influence of lifestyle on CVD over 20 years and found that the population attributable risk for CVD was $30 \%$, and compared to those who did no physical activity and had the least healthy profile, individuals in the healthiest category had the greatest reduced risk $0.32 \quad(\mathrm{CI}=0.15-0.69) \quad$ [18]. In 40,708 participants comparing lifestyle scores over an 8-year follow-up period, those in the healthy group had a significantly reduced risk of CVD mortality $(\mathrm{RR}=0.53, \mathrm{CI}=$ $0.37-0.77)$ compared to those in the unhealthy group [15]. Hulsegge and Colleagues (2016) found that independent of baseline lifestyle behaviour reporting when re-measured later, each decrement in lifestyle factors was associated with a $35 \%$ higher risk of CVD, and individuals who maintained their healthy lifestyle over time (4 to 5 factors) had 2.5 times lower risk of CVD (HR = $0.43, \mathrm{CI}=0.25-0.63)$ compared to those who maintained an unhealthy lifestyle profile (0 to 1 factors) [23].

Examining various sub-groups, Petersen and Colleagues (2015) found a significant risk reduction amongst those men and women who achieved all five lifestyle behaviour points compared to those who did not [31]. For CVD mortality, the adjusted hazard ratio for those in the category of 4-5 positive lifestyle behaviours compared to those with 0 was $0.20(\mathrm{CI}=0.14$ $0.0 .29)$ for men and $0.21(\mathrm{CI}=0.11-0.41)$ for women. In a population-based cohort of 60 -year-old men $(n=2039)$ and women $(n=2193)$ after 11 years of follow-up, for those categorised as very healthy compared to unhealthy, the respective hazard ratios were $0.25(\mathrm{CI}=0.15-0.44)$ for men and $0.35(\mathrm{CI}=0.23-0.54)$ for women [30]. Examining men only (we excluded women because one of the scoring criteria included breastfeeding), Vergnaud and others (2013) found that after 12.8 years, men in the healthiest category compared to the least healthy category $(\mathrm{RR}=0.64, \mathrm{CI}=0.50-0.82)$ were less likely to die of CVD [37]. Moreover, the largest study cohort $(n=$ $111,966)$ found that achieving more recommended behaviours categorized as healthy compared to least healthy had a reduced risk of CVD mortality in both men $(R R=0.52, C I=0.45-0.59)$ and women $(R R=0.42$, $\mathrm{CI}=0.35-0.51)$ over 14 years of follow-up [35].

When examining the dual-association between sedentary behaviour, specifically sitting time, and physical activity in women, Chomistek and Colleagues (2013) found a non-statistically significant interaction between sitting time and physical activity with CVD $\left(p_{\text {interaction }}=\right.$ 0.94) [33]. Similarly, O’Donovan and Colleagues (2017) examined the dual-associations between physical activity and smoking behaviour in 106,341 participants and found that after 9.4 years, those who were regular exercisers of over $60 \mathrm{~min}$ a week and did not smoke had a reduced risk of CVD mortality $(\mathrm{RR}=0.27, \mathrm{CI}=0.18$ 0.42 ) compared to those who did not exercise and were current smokers [21].

Similar results were evident for heart failure when examining men and women separately [34]. Wang and Colleagues (2011) examined 18,346 men and 19,729 women and followed them for a median of 14.1 years. They found that for both men and women, having a healthier lifestyle profile resulted in a reduced risk of heart failure [34]. Having all 4 lifestyle factors compared to none, resulted in a hazard ratio of $0.31(\mathrm{CI}=0.17$ $0.56)$ for men and, $0.19(\mathrm{CI}=0.09-0.40)$ for women. In a sample of 33,966 men and 30,713 women followed for 13 years, the relative risks for heart disease in the 
healthiest lifestyle profile compared to the least healthy profile, which included those with 0 healthy lifestyle risk factors, was $0.38(0.28-0.53)$ in men and $0.28(0.19$ 0.41 ) in women [24]. For stroke, it was found that compared to the least healthy lifestyle profile (no lifestyle points), those with the healthiest profile (5 lifestyle points) had a relative risk of $0.38(\mathrm{CI}=0.20-0.73)$ [32]. Finally, examining incident myocardial infarction in 20, 721 men, followed for 11 years, having all 5 positive lifestyle points compared to none gave a relative risk of 0.14 $(\mathrm{CI}=0.04-0.43)$, and these researchers concluded that this combination of positive behaviours could have prevented $79 \%(\mathrm{CI}=0.34-0.93 \%)$ of the events in this study cohort [25].

\section{Cancers}

A total of 12 studies assessed cancer as an outcome. Eight studies focused on cancer broadly [15-17, 21, 27, $31,35,37]$. Three studies examined colorectal cancer $[20,26,39]$, and one study examined breast cancer [36].

In general, engaging in a higher number of healthy behaviours compared to less, led to greater protection against most cancers. Kabat and Colleagues (2015) followed 476,396 participants for 10.5 years on average, during which time, 73,784 people had a first incident cancer diagnoses and 16,193 people died of cancer [27]. Similarly, in 40,708 participants after 8-years of followup, those in the healthy group compared to the least healthy group had a reduced risk of cancer mortality $(\mathrm{RR}=0.82, \mathrm{CI}=0.53-0.86) \quad[15]$. Moreover, Kaavik and colleagues followed UK adults for 20 years where 18 deaths of 4886 deaths were attributed to cancer and they found that those participants with all positive health behaviours and those taking more physical activity versus those with no positive health behaviours and reporting no physical activity had a hazard ratio of $0.29(\mathrm{CI}=$ 0.15-0.60) [18].

Looking at subgroups, McCullough and others (2011) examined 111,966 non-smoking men and women and the relative risk for those in the healthiest category of lifestyle behaviour (7-8) versus those in the least healthy category $(0-2)$ and found that risk was $0.70(\mathrm{CI}=0.61-$ $0.80)$ for men and $0.76(\mathrm{CI}=0.65-0.89)$ for women [35]. This was similar to Vergnaud and Colleagues (2013) where men's adjusted risk was $0.86(\mathrm{CI}=0.69-1.07)$ for cancer after a median of 12.7 years of follow-up [37]. Additionally, after 10.3 years of follow-up of 59,941 Koreans, Yun and colleagues found that the risk for cancer mortality was $0.42(\mathrm{CI}=0.35-0.69)$ in men and 0.50 (0.23-1.08) in women [19]. Petersen and colleagues (2015) explored cancer mortality risk in Danish men and women over a 14-year period and found that adherence to 4-5 positive lifestyle behaviours versus 0 positive lifestyle behaviours gave an adjusted hazard ratio of 0.33
(0.26-0.42) for cancer mortality in men and $0.41(0.29$ 0.58 ) in women [31]. Lastly, O'Donovan and Colleagues (2017) examined the dual-associations between physical activity and smoking behaviour and found that regular exercisers who did not smoke had a greater reduced risk of cancer mortality ( $\mathrm{RR}=0.30, \mathrm{CI}=0.22-0.41$ ) compared to those who never exercised and were current smokers [21].

Three cohort studies examined colorectal cancer specifically. In a sample of 59,503 men followed for 9.28 years, Zhang and Colleagues (2017) found that each increment in score in having a healthier lifestyle was associated with a $17 \%$ reduced risk of colorectal cancer $(\mathrm{HR}=0.83 ; \mathrm{CI}=0.78-0.89), 27 \%$ for rectal cancer $(\mathrm{HR}=$ $0.73 ; \mathrm{CI}=0.66-0.82)$, and $10 \%$ for colon cancer $(\mathrm{HR}=$ $0.90 ; \mathrm{CI}=0.83-0.99) \quad[20]$. Kirkegaard and Colleagues (2010) found that higher physical activity levels and choosing more positive lifestyle behaviours was associated with a lower risk of colorectal cancer in a sample of 55,487 men and women, incidence rate ratio $0.89(\mathrm{CI}=$ 0.82-0.96) [26]. However, Nomura and Colleagues (2016) when examining incidence in African American women, found that adherence to more positive behaviours were not associated with colorectal cancer risk [39]. Lastly, the one cohort study examining breast cancer risk in postmenopausal women $(n=242,912)$ found that having a higher score of healthier behaviours (score of 4 compared to 1) reduced the risk of breast cancer incidence after a median of 10.9 years of follow-up (adjusted hazard ratio $=0.74, \mathrm{CI}=0.66-0.83$ ) [36].

\section{High quality studies}

When we included more stringent criteria, restricting to studies with $8+$ years of follow-up, and the use of a structured interview or a validated physical activity measure, we had 11 remaining studies (Table 2). Outcomes included in the final analysis were 7 for all-cause mortality, 6 for cardiovascular diseases, and 7 for cancers. Additionally, some studies performed subgroup analysis by sex, and others targeted only one sex specifically. Overall, trends suggested that engaging in a greater number of positive health behaviours resulted in reduced risk of death, and being less likely to develop and die of cardiovascular diseases, and cancers.

Figure 2 examines the risk relationship between those in each cohort that were categorised as the healthiest (reference group) compared to those in the least healthy category. The results and evidence are quite strong that less healthy lifestyle behaviour puts one at a higher risk of death and cardiovascular disease incidence or mortality. Although the high-quality articles examining cancer outcomes displayed a similar trend to that seen in the all-cause mortality and CVD articles, the risk 
Table 2 Description of studies with a validated physical activity measure and 8+ years of follow-up $(n=11)$

\begin{tabular}{|c|c|c|c|c|c|}
\hline $\begin{array}{l}\text { Author(s), } \\
\text { year }\end{array}$ & Physical activity (PA) in best group & Best Group & Worst Group & Main Finding & $\begin{array}{l}\text { Effect of } \\
\text { increasing PA on } \\
\text { risk }\end{array}$ \\
\hline $\begin{array}{l}\text { Shaw and } \\
\text { Agahi, } 2014 \\
\text { [18] }\end{array}$ & $\begin{array}{l}\text { Participants needed } 2 \text { PA points. } \\
\text { Received } 1 \text { point if they reported that } \\
\text { they 'sometimes' did gardening, hunting, } \\
\text { and dancing and } 2 \text { points if they } \\
\text { reported 'often' during the past } 12\end{array}$ & $\begin{array}{l}\text { Active/Non- } \\
\text { smoking } \\
\text { (reference) }\end{array}$ & $\begin{array}{l}\text { Discontinued } \\
\text { activity/ } \\
\text { Persistent } \\
\text { smoking }\end{array}$ & $\begin{array}{l}\text { All participants with high PA who were } \\
\text { non-smokers had a significantly reduced } \\
\text { mortality risk compared to no PA and } \\
\text { smokers, } 0.48(\mathrm{Cl}=0.36-0.67)^{\mathrm{a}} \text {. }\end{array}$ & $\downarrow$ Mortality risk \\
\hline
\end{tabular}

Hulsegge

et al., 2016

[24]
Yun et al., PA $\geq 3$ times/week

2012 [20] months. Any sports participation (often or sometimes) was rewarded 2 points.

$\mathrm{PA} \geq 3.5 \mathrm{~h} /$ week at both waves.

\section{4 to 5}

al., 2010

[19]

Larsson et

$\mathrm{PA} \geq 150 \mathrm{~min} /$ week

al., 2016

[25]

Åkesson et al., 2014 [26]

Kirkegaard et al., 2010 [27]

$>30$ mins of moderate activity/day or day

Nomura et $\geq 3-4 \mathrm{~h} /$ week vigorous PA or $\geq 5-6 \mathrm{~h} /$ al., 2016 week walking. $\begin{array}{ll}4 \text { lifestyle } & 0 \text { lifestyle } \\ \text { factor points } & \text { factor points }\end{array}$

5 lifestyle 0 lifestyle factor points factor points healthy

factors at baseline and

follow-up

\section{0 to 1 factors} at baseline and followup

0 lifestyle factor points

4 lifestyle factor points

0 lifestyle 4 lifestyle factor points factor points

5 lifestyle

0 lifestyle

Each increase in number of healthy lifestyle factors at a later date led to a reduced risk of CVD and all-cause mortality. Individuals who maintained a healthy lifestyle profile had a $57 \%$ lower risk of CVD, $0.43(\mathrm{Cl}=0.25-0.63)^{\mathrm{a}}$, and $60 \%$ lower risk of all-cause mortality, $0.40(\mathrm{Cl}=0.22$ $0.73)^{a}$ compared to those with an unhealthy lifestyle.

In men and women, compared to those having all 4 of the poor lifestyle factor points, those with 0 poor lifestyle factor points and high PA men had a $0.42(\mathrm{Cl}=$ $0.35-0.69)^{\mathrm{a}}$ reduced risk of cancer mortality and women had a $0.50(0.23-$ $1.08)^{a}$ reduced risk. For all-cause mortality, men had a $0.50(\mathrm{Cl}=0.40-0.63)^{\mathrm{a}}$ reduced risk, and women had a $0.48(\mathrm{Cl}=0.28$ $0.82)^{a}$ reduced risk.

Compared to those in the least healthy group (4 points and no PA) those with all healthy lifestyle beahviours and high PA (0 points) was associated with a reduced risk of death (all-cause mortality, CVD, and cancer). Morality risk was $0.29(\mathrm{Cl}=$ $0.19-0.43)^{\mathrm{a}}$ for death by all-causes, 0.32 $\left(C l=0.15-0.69^{\mathrm{a}}\right.$ for $C V D$ and $0.29(\mathrm{Cl}=$ $0.15-0.60)^{\mathrm{a}}$ for cancer in the healthiest group (0 points) group at baseline compared to the least healthy (4 points).

Compared with those with no healthy lifestyle factors, the multivariable relative risks of heart failure for those with all 4 lifestyle factors were $0.38(\mathrm{Cl}=0.28-0.53)^{\mathrm{a}}$ in men and $0.28(\mathrm{Cl}=0.19-0.41)^{\mathrm{a}}$ in women

Compared with those with 0 lifestyle factor points, men with all 5 lifestyle factor points had a relative risk of 0.14 (95\%Cl: 0.04-0.43) ${ }^{\mathrm{a}}$. This profile could prevent $79 \%(\mathrm{Cl}=34-93 \%)$ of all myocardial events based on this study population's characteristics.

Compared with the worst lifestyle behavior's, participants who had the best behaviors had a $58 \%$ lower risk of developing colorectal cancer, but this was non-significant due to the wide confidence intervals (0.42, Cl: 0.13-1.32) .

7 lifestyle 0 lifestyle factor points factor points
Regardless of the modeling approach used, adherence to a greater number of recommendations was not significantly associated with reduced colorectal cancer risk, $1.01(95 \% \mathrm{Cl}=0.82-1.24)$. Similar results were observed for colon cancer, $\downarrow$ All-cause mortality and CVD

$\downarrow$ All-cause mortality and Cancer mortality

$\downarrow$ Mortality for all-causes, CVD, and Cancer

$\downarrow$ Risk of heart

failure

$\downarrow$ Myocardial infarction risk

NS Colorectal cancer incidence

NS Colorectal cancer risk NS Colon cancer risk 
Table 2 Description of studies with a validated physical activity measure and 8+ years of follow-up ( $n=11)$ (Continued)

\begin{tabular}{|c|c|c|c|c|c|}
\hline $\begin{array}{l}\text { Author(s), } \\
\text { year }\end{array}$ & Physical activity (PA) in best group & Best Group & Worst Group & Main Finding & $\begin{array}{l}\text { Effect of } \\
\text { increasing PA on } \\
\text { risk }\end{array}$ \\
\hline & & & & $1.06(95 \% \mathrm{Cl}=0.84-1.35)$ & \\
\hline $\begin{array}{l}\text { Zhang et } \\
\text { al., } 2017 \\
{[21]}\end{array}$ & $\begin{array}{l}\geq 150 \mathrm{~min} / \text { week of moderate-to-vigorous- } \\
\text { intensity PA }\end{array}$ & $\begin{array}{l}4-5 \text { lifestyle } \\
\text { factor points }\end{array}$ & $\begin{array}{l}0 \text { lifestyle } \\
\text { factor points }\end{array}$ & $\begin{array}{l}\text { Compared with the least healthy lifestyle } \\
\text { group, those in the healthies lifestyle } \\
\text { group had a hazard ratio of } 0.65(95 \% \mathrm{Cl}= \\
0.47-0.90)^{\mathrm{a}} \text { for colon cancer, } 0.35 \\
(95 \% \mathrm{Cl}=0.24-0.52)^{\mathrm{a}} \text { for rectal cancer, and } \\
0.50(95 \% \mathrm{Cl}=0.39-0.65)^{\mathrm{a}} \text { for colorectal } \\
\text { cancer. }\end{array}$ & $\begin{array}{l}\text { NS colon cancer } \\
\text { risk } \\
\downarrow \text { Rectal cancer } \\
\text { risk } \\
\downarrow \text { Colorectal } \\
\text { cancer risk }\end{array}$ \\
\hline $\begin{array}{l}\text { O'Donovan } \\
\text { et al., } 2017 \\
\text { [22] }\end{array}$ & $\geq 60 \mathrm{~min} /$ week of PA & $\begin{array}{l}\geq 60 \mathrm{~min} / \\
\text { week of PA } \\
\text { and non- } \\
\text { smokers }\end{array}$ & $\begin{array}{l}\text { No exercise } \\
\text { and current } \\
\text { smokers }\end{array}$ & $\begin{array}{l}\text { Those who exercised for over } 60 \mathrm{~min} / \\
\text { week and were never smokers compared } \\
\text { to those who did no exercise and were } \\
\text { current smokers had a } 0.29(\mathrm{Cl}=0.24- \\
0.36)^{\mathrm{a}} \text { reduced risk for all-cause mortality, } \\
0.27(\mathrm{Cl}=0.18-0.42)^{\mathrm{a}} \text { for } \mathrm{CVD} \text { mortality } \\
\text { and } 0.30(\mathrm{Cl}=0.22-0.41)^{\mathrm{a}} \text { for cancer } \\
\text { mortality. }\end{array}$ & $\begin{array}{l}\downarrow \text { All-cause mor- } \\
\text { tality, } \downarrow \text { CVD } \\
\text { mortality, and } \downarrow \\
\text { cancer mortality }\end{array}$ \\
\hline $\begin{array}{l}\text { Larsson et } \\
\text { al., } 2017 \\
{[23]}\end{array}$ & $\geq 150 \mathrm{~min} /$ week of PA & $\begin{array}{l}4 \text { lifestyle } \\
\text { factor points }\end{array}$ & $\begin{array}{l}0 \text { lifestyle } \\
\text { factor points }\end{array}$ & $\begin{array}{l}\text { Compared to the least healthy group, } \\
\text { those in the healthiest group the hazard } \\
\text { ratio for all-cause mortality for men was } \\
0.47(95 \% \mathrm{Cl}=0.44-0.51)^{\mathrm{a}} \text { and for women } \\
\text { this was } 0.39(95 \% \mathrm{Cl}=0.35-0.44)^{\mathrm{a}} \text {. }\end{array}$ & $\begin{array}{l}\downarrow \text { All-cause } \\
\text { mortality }\end{array}$ \\
\hline
\end{tabular}

associations were not as large, and the findings for colorectal cancer were mixed.

\section{Discussion}

Overall, we aimed to examine the association between how higher levels of physical activity in combination with additional positive lifestyle behaviours impacts cardiovascular disease, cancer, and all-cause mortality. Across the 25 eligible studies, those participants who reported higher levels of physical activity combined with achieving other health behaviour goals compared to those who were categorised as physically inactive and did not achieve other positive lifestyle goals, were at least half as likely to experience an incident CVD event, die from CVD, or die from any cause. These findings were consistent across participant age, sex, and study length of follow-up, and even after excluding lower quality studies. We observed a similar trend among the few studies which were restricted to cancer outcomes. Although limited, evidence from high quality cohorts suggests that the categorisation of multiple lifestyle risks groups, and thus the group someone is categorised into, is strongly predictive of long-term mortality and cardiovascular and cancer morbidity.

To date, there have been few high-quality studies examining combined effects of physical activity and lifestyle risk factors on cardiovascular diseases, cancers, and mortality risk. We found that most studies were limited by bias attributable to residual confounding, reverse causality by pre-existing disease, and measurement error with self-report data. In most prospective studies examined, physical activity assessed at baseline was used to investigate the association of activity with health outcomes many years later. As a result, these studies do not accurately characterise activity during long periods of follow-up, since measurement error could occur at the time of assessment, and physical activity behaviours may change over time [40, 41]. Moreover, while measurement error may be less of a concern for other behavioural risk factors (except diet), changes over time are still common, and these errors may result in regression dilution bias. Regression dilution bias in these studies could have resulted in the attenuation in the estimates of the risk associations between behavioural risk factors assessed at baseline and the health outcome of interest [41]. Resurveys on a representative sample of study participants can be used to correct for regression dilution [40], and allow behavioural risk factor information to more accurately reflect the "usual" exposure levels over the follow-up period [41].

Additionally, we found that across studies, reporting of physical activity has been heterogeneous. Physical activity was measured in different contexts and environments, and generally included different scores for intensity, frequency and duration measurements through self-report. Without standardised agreement across publications, readers face several challenges in determining the implications and impact of the associations between lifestyle risk factors and disease outcomes [42]. 


\begin{tabular}{|c|c|c|c|c|c|c|}
\hline Study & Outcome & Quality & $\begin{array}{l}\text { Size of } \\
\text { sample }\end{array}$ & Group & & RR (95\% Cl) \\
\hline \multicolumn{7}{|l|}{ All Cause Mortality } \\
\hline Shaw and Agahi, 2014 & M & 10 & 1682 & All & $\rightarrow-$ & $2.10(1.50,2.80)$ \\
\hline Yun et al., 2012 & M & 9 & 31850 & Men & $=$ & $2.00(1.58,2.52)$ \\
\hline Larsson et al., 2017 & M & 9 & 33454 & Men & - & $2.13(1.96,2.27)$ \\
\hline Larsson et al., 2017 & M & 9 & 30639 & Women & 들 & $2.56(2.27,2.86)$ \\
\hline O'Donovan et al., 2017 & M & 9 & 106337 & All & - & $3.38(2.76,4.13)$ \\
\hline Yun et al., 2012 & M & 9 & 28091 & Women & $\longrightarrow$ & $2.09(1.22,3.59)$ \\
\hline Hulsegge et al., 2016 & M & 8 & 5263 & All & $\longrightarrow$ & $2.50(1.37,4.55)^{*}$ \\
\hline Kvaavik et al., 2010 & M & 8 & 4886 & All & $\longrightarrow$ & $3.49(2.31,5.26)$ \\
\hline \multicolumn{7}{|l|}{ CVD } \\
\hline Akesson et al., 2014 & IMI & 9 & 20721 & Men & - & $7.14(2.33,25.0)$ \\
\hline Larsson et al., 2016 & IHF & 9 & 33966 & Men & $\rightarrow$ & $2.63(1.89,3.57)^{*}$ \\
\hline Larsson et al., 2016 & IHF & 9 & 30713 & Women & $\rightarrow$ & $3.57(2.44,5.26)$ * \\
\hline O'Donovan et al., 2017 & CVDM & 9 & 106337 & All & $\longrightarrow$ & $3.64(2.40,5.53)$ \\
\hline Kvaavik et al., 2010 & CVDM & 8 & 4886 & All & $\longrightarrow$ & $3.14(1.57,6.29)^{*}$ \\
\hline Hulsegge et al., 2016 & ICVD & 8 & 5263 & All & $\rightarrow$ & $2.33(1.59,4.00)$ \\
\hline \multicolumn{7}{|l|}{ Cancers } \\
\hline O'Donovan et al., 2017 & M & 9 & 106337 & All & $\rightarrow$ & $3.32(2.44,4.51)$ \\
\hline Yun et al., 2012 & M & 9 & 31850 & Men & $\rightarrow-$ & $2.04(1.45,2.87)$ \\
\hline Yun et al., 2012 & M & 9 & 28091 & Women & & $2.00(0.93,4.29)$ \\
\hline Kvaavik et al., 2010 & M & 8 & 4886 & All & & $3.35(1.67,6.70)$ \\
\hline Kirkegaard et al., 2010 & ICRC & 8 & 55487 & All & & $1.12(1.04,1.22)$ \\
\hline Kirkegaard et al., 2010 & ICC & 8 & 55487 & All & & $1.14(1.02,1.25)$ \\
\hline Kirkegaard et al., 2010 & IRC & 8 & 55487 & All & $=$ & $1.12(0.98,1.28)$ \\
\hline Nomura et al., 2016 & ICRC & 8 & 49103 & Women & & $1.01(0.82,1.24)_{\star}$ \\
\hline Nomura et al., 2016 & $\mathrm{ICC}$ & 8 & 49103 & Women & 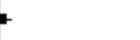 & $1.06(0.84,1.35)$ \\
\hline Zhang et al., 2017 & ICC & 8 & 59503 & Men & $\leftarrow$ & $1.54(1.11,2.13)$ \\
\hline Zhang et al., 2017 & IRC & 8 & 59503 & Men & $\longrightarrow$ & $2.86(1.92,4.12)$ \\
\hline \multirow[t]{2}{*}{ Zhang et al., 2017} & ICRC & 8 & 59503 & Men & - & $2.00(1.54,2.56)$ \\
\hline & & & & & 3 & \\
\hline \multicolumn{7}{|c|}{ 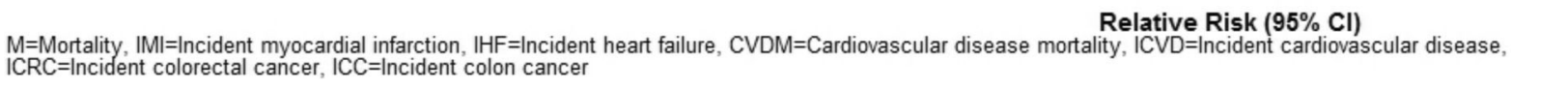 } \\
\hline \multicolumn{7}{|c|}{ Fig. 2 Forest plot of risk comparing those who were categorised as healthiest compared to those who were categorised as least healthy } \\
\hline
\end{tabular}

All studies included in this review assessed multiple behavioural risk factors using co-occurrence methodologies. These methods have limitations as they require dichotomisation of lifestyle behaviours into 'risky/unhealthy' versus 'not risky/healthy' [6], and thereby limit conclusions that can be made on a dose response. In addition, co-occurrence methodologies provide no indication of whether the co-occurrence of behaviours is, in part or in whole, the result of the association between the behaviours [6]. Future research needs to explore the use of new analysis approaches, such as cluster analysis, to examine the association of multiple behavioural risk factors on health outcomes. For example, cluster analysis is not restricted to dichotomous behaviour categorisation, and allows the identification of association patterns using multiple levels for each variable, thereby providing answers on dose response [1].

Our findings suggest that health researchers, policy makers, and clinicians need to shift their focus from the independent effects to the combined effects of lifestyle behaviours on disease outcomes. Further investment in high quality research addressing this objective is warranted. Traditionally, the UK Department of Health has not adopted a holistic approach to preventive medicine [1], perhaps because policies on lifestyle risk factors have been separated into individual risks. The resulting focus has been on independent risk factors and their impact on diseases, rather than how multiple lifestyle risk factors are jointly distributed across the population, and how these impact disease outcomes [1].

\section{Limitations}

Despite our rigorous title and abstract screening protocol, search terms for physical activity may have been omitted from the title and abstract and thus gone undetected. This is possible because, if a study focused predominately on smoking and alcohol, although physical activity could have been included in the full-text, it may not have been mentioned at the abstract level because this exposure was not one of the main exposures of 
interest. Additionally, each observational study adjusted by using different covariates, measuring exposures differently, and had different follow-up times. This may have led to the high heterogeneity observed in our review, thereby limiting our ability to conduct a meta-analysis. Given the many differences in how each study categorised and measured lifestyle behaviours, as well as, the differences in the number of behaviours included in each study, we were unable to compute an $\mathrm{I}^{2}$ statistic which would have provided a useful measure of the variation across these studies rather than that of chance.

Across all studies, physical activity was measured by using self-report or structured interviews. Therefore, recall bias within the reviewed results must be considered. We performed detailed data extraction of all included studies, and completed the NOS to assess study quality. Future work should apply more sophisticated and objective physical activity measurement methods. Also, there was little consistency across studies regarding how the frequency, intensity and duration of physical activity were recorded. Limiting this review to observational research, which in many cases only reported physical activity at baseline, allowed for conclusions to only consider physical activity during the time of examination. The re-measurement or continuous monitoring of physical activity levels between exposure measurement and outcome occurrence would allow for more accurate conclusions, and should be a focus of future work.

\section{Conclusions}

In summary, this was the first global systematic review of adults to examine the combined effect of physical activity with other positive lifestyle behaviours and its relationship with cardiovascular disease, cancer, and mortality from any cause. High levels of physical activity when combined with other positive lifestyle choices are associated with better health outcomes. Physical activity is only one part of multifaceted lifestyle behaviours, and applying new approaches to studying the complex relationships between multiple behavioural risk factors, including physical activity should be a priority.

\section{Additional files}

Additional file 1: Physical activity + risk factor(s) and incidence and mortality of non-communicable diseases. Data extraction form. (PDF $72 \mathrm{~kb}$ )

Additional file 2: Search Strategy. (DOC $63 \mathrm{~kb}$ )

Additional file 3: EMBASE. Search terms. (PDF 59 kb)

\section{Abbreviations}

CHD: coronary heart disease; Cl: confidence interval; CVD: cardiovascular disease; HR: hazard ratio; NOS: Newcastle-Ottawa Scale; PRISMA: Preferred Reporting Items for Systematic Reviews and Meta-Analyses; RR: relative risk; UK: United Kingdom

\section{Acknowledgements}

The authors would like to thank Nia Roberts for developing the electronic search strategy for this systematic review.

\section{Authors' contributions}

The search was performed by $\mathrm{J}$, exclusion by titles for all returned results was performed by $\mathrm{J}$, and a $10 \%$ double review of titles was completed by $J L$ and MA. All abstracts were reviewed by $J$ and CF. The remaining full-text articles were read in-detail by JL. Data extraction was completed by JL. Quality assessment completed independently by $\mathrm{J}$ and FLW. All authors read and approved the final manuscript.

\section{Funding}

Jason Lacombe is funded by a Non-Clinical PhD Studentship from the British Heart Foundation. The BHF had no influence or involvement in the creation and submission of this systematic review.

\section{Availability of data and materials}

Not applicable. However, if the reader wishes to perform the search again they can use the search strategy found in the supplementary materials.

Ethics approval and consent to participate

Not applicable.

\section{Consent for publication}

Not applicable.

\section{Competing interests}

The authors declare that they have no competing interests.

\section{Author details}

${ }^{1}$ Cancer Epidemiology Unit, University of Oxford, Oxford, UK. ${ }^{2}$ Centre for Exercise, Nutrition and Health Sciences, School of Policy Studies, University of Bristol, Bristol, UK. ${ }^{3}$ Unit of Health Care Epidemiology, Big Data Institute, Nuffield Department of Population Health, NIHR Oxford Biomedical Research Centre, University of Oxford, Old Road, Oxford OX3 7LF, UK.

Received: 12 June 2018 Accepted: 22 May 2019

Published online: 08 July 2019

References

1. Buck D, Frosini F. Clustering of unhealthy behaviours over time implications for policy and practice. Kings Fund. 2012:1-24. www.kingsfund. org.uk.

2. World Health Organisation. Global health risks: Mortality and burden of disease attributable to selected major risks. Geneva: World Health Organisation. https://www.who.int/healthinfo/global_burden_disease/ GlobalHealthRisks report full.pdf.

3. Yusuf S, Hawken S, Ounpuu S, Dans T, Avezum A, Lanas F, et al. Effect of potentially modifiable risk factors associated with myocardial infarction in 52 countries (the INTERHEART study): case control study. Lancet. 2004;364: 937-52.

4. Forouzanfar MH, Afshin A, Alexander LT, Biryukov S, Brauer M, Cercy K, et al. Global, regional, and national comparative risk assessment of 79 behavioural, environmental and occupational, and metabolic risks or clusters of risks, 1990-2015: a systematic analysis for the global burden of disease study 2015. Lancet. 2016;388:1659-724.

5. Scarborough P, Wickramasinghe K, Bhatnagar P, Rayner M. Trends in coronary heart disease, 1961-2011. Hear Dis. 2011:1961-2011.

6. McAloney K, Graham H, Law C, Platt L. A scoping review of statistical approaches to the analysis of multiple health-related behaviours. Prev Med (Baltim). 2013:56:365-71.

7. Chief Medical Officer. Physical activity benefits infographic for adults and older adults. UK Chief Med Off Guidel. 2011;2015. https://www.gov.uk/ government/uploads/system/uploads/attachment_data/file/541233/ Physical_activity_infographic.PDF.

8. Brooks J, Ahmad I, Easton G. Promoting physical activity: the general practice agenda. Br J Gen Pract. 2016;66:454-5.

9. Butler CC, Simpson SA, Hood K, Cohen D, Pickles T, Spanou C, et al. Training practitioners to deliver opportunistic multiple behaviour change counselling in primary care: a cluster randomised trial. BMJ. 2013;346:1-25. 
10. Dyakova M, Shantikumar S, Colquitt JL, Drew CM, Sime M, Maciver J, et al. Systematic versus opportunistic risk assessment for the primary prevention of cardiovascular disease. Cochrane Database Syst Rev. 2016;2016:CD010411.

11. Lacombe J, Foster C, Armstrong M, Wright L. Physical activity and other risk factors: relations to all-cause mortality and non- communicable diseases. A systematic review. Int Prospect Regist Syst Rev. 2017:1-4.

12. Who WHO. Global recommendations on physical activity for health, vol. 60 . Geneva: World Heal Organ; 2010. https://doi.org/10.1080/ 11026480410034349.

13. Wells GA, Shea B, O'Connell D, Peterson J, Welch V, Losos M, et al. The Newcastle-Ottawa Scale (NOS) for assessing the quality of nonrandomized studies in meta-analyses. Ottawa Hosp Res Inst. 2013:1-4. https://doi.org/10. 2307/632432

14. Prinelli F, Yannakoulia M, Anastasiou CA, Adorni F, Di Santo SG, Musicco M, et al. Mediterranean diet and other lifestyle factors in relation to 20-year allcause mortality: a cohort study in an Italian population. Br J Nutr. 2015;113: 1003-11. https://www.ncbi.n/m.nih.gov/pubmed/25746109.

15. Fazel-Tabar Malekshah A, Zaroudi M, Etemadi A, Islami F, Sepanlou S, Sharafkhah $\mathrm{M}$, et al. The combined effects of healthy lifestyle behaviors on all-cause mortality: the Golestan cohort study. Arch Iran Med. 2016;19:75261. https://www.ncbi.n/m.nih.gov/pubmed/27845543.

16. Eriksen A, Tillin T, Connor LO, Brage S, Hughes A, Mayet J, et al. The impact of health behaviours on incident cardiovascular disease in Europeans and South Asians - A prospective analysis in the UK SABRE study. PLoS One. 2015;10:e0117364. https://journals.plos.org/plosone/article?id=10.1371/ journal.pone.0117364.

17. Shaw BA, Agahi N. Smoking and physical inactivity patterns during midlife as predictors of all-cause mortality and disability: a 39-year prospective study. Eur J Ageing. 2014;11:195-204. https://www.ncbi.nlm.nih.gov/pmc/ articles/PMC4191664/.

18. Kvaavik E, Batty GD, Ursin G, Huxley R, Gale CR. Influence of individual and combined health behaviors on total and cause-specific mortality in men and women: the United Kingdom health and lifestyle survey. Arch Intern Med. 2010;170:711-8. https://www.ncbi.n/m.nih.gov/pubmed/20421558.

19. Yun JE, Won S, Kimm H, Jee SH. Effects of a combined lifestyle score on 10year mortality in Korean men and women: a prospective cohort study. BMC Public Health. 2012;12:673. https://bmcpublichealth.biomedcentral.com/ articles/10.1186/1471-2458-12-673.

20. Zhang Q-L, Zhao L-G, Li H-L, Gao J, Yang G, Wang J, et al. The joint effects of major lifestyle factors on colorectal cancer risk among Chinese men: a prospective cohort study. Int J Cancer. 2017;142(6).

21. O'Donovan G, Hamer M, Stamatakis E. Relationships between exercise, smoking habit and mortality in more than 100,000 adults. Int J Cancer. 2017;140:1819-27.

22. Larsson SC, Kaluza J, Wolk A. Combined impact of healthy lifestyle factors on lifespan: two prospective cohorts. J Intern Med. 2017;282:209-19.

23. Hulsegge $G$, Looman M, Smit HA, Daviglus ML, van der Schouw YT, Verschuren WMM. Lifestyle changes in young adulthood and middle age and risk of cardiovascular disease and all-cause mortality: the Doetinchem cohort study. J Am Heart Assoc. 2016;5:e002432. https://www.ncbi.nlm.nih. gov/pubmed/26764411.

24. Larsson SC, Tektonidis TG, Gigante B, Akesson A, Wolk A. Healthy lifestyle and risk of heart failure: results from 2 prospective cohort studies. Circ Heart Fail. 2016;9:e002855. https://www.ncbi.nlm.nih.gov/pubmed/27072861.

25. Akesson A, Larsson SC, Discacciati A, Wolk A. Low-risk diet and lifestyle habits in the primary prevention of myocardial infarction in men: a population-based prospective cohort study. J Am Coll Cardiol. 2014;64: 1299-306. https://doi.org/10.1016/j.jacc.2014.06.1190.

26. Kirkegaard H, Johnsen NF, Christensen J, Frederiksen K, Overvad K, Tjonneland A. Association of adherence to lifestyle recommendations and risk of colorectal cancer: a prospective Danish cohort study. BMJ. 2010;341: c5504. https://www.bmj.com/content/341/bmj.c5504

27. Kabat GC, Matthews CE, Kamensky V, Hollenbeck AR, Rohan TE. Adherence to cancer prevention guidelines and cancer incidence, cancer mortality, and total mortality: a prospective cohort study. Am J Clin Nutr. 2015;101:558-69. https://www.ncbi.nlm.nih.gov/pubmed/25733641.

28. Behrens G, Fischer B, Kohler S, Park Y, Hollenbeck AR, Leitzmann MF. Healthy lifestyle behaviors and decreased risk of mortality in a large prospective study of U.S. women and men. Eur J Epidemiol. 2013;28:361-72. https://www.ncbi.nlm.nih.gov/pubmed/23532745.
29. Shaw BA, Agahi N. A prospective cohort study of health behavior profiles after age 50 and mortality risk. BMC Public Health. 2012;12:803. https:// bmcpublichealth.biomedcentral.com/articles/10.1186/1471-2458-12-803.

30. Carlsson AC, Wandell PE, Gigante B, Leander K, Hellenius ML, De Faire U. Seven modifiable lifestyle factors predict reduced risk for ischemic cardiovascular disease and all-cause mortality regardless of body mass index: a cohort study. Int J Cardiol. 2013;168:946-52. https://www.ncbi.nlm. nih.gov/pubmed/23181992.

31. Petersen KEN, Johnsen NF, Olsen A, Albieri V, Olsen LKH, Dragsted LO, et al. The combined impact of adherence to five lifestyle factors on all-cause, cancer and cardiovascular mortality: a prospective cohort study among Danish men and women. Br J Nutr. 2015;113:849-58 https://www.ncbi.nlm. nih.gov/pubmed/25690300.

32. Larsson SC, Akesson A, Wolk A. Healthy diet and lifestyle and risk of stroke in a prospective cohort of women. Neurology. 2014;83:1699-704. https:// www.ncbi.nlm.nih.gov/pubmed/25298305.

33. Chomistek AK, Manson JE, Stefanick ML, Lu B, Sands-Lincoln M, Going SB, et al. Relationship of sedentary behavior and physical activity to incident cardiovascular disease: results from the Women's health initiative. J Am Coll Cardiol. 2013;61:2346-54. https://www.ncbi.nlm.nih.gov/pubmed/23583242.

34. Wang Y, Tuomilehto J, Jousilahti P, Antikainen R, Mahonen M, Katzmarzyk $P T$, et al. Lifestyle factors in relation to heart failure among Finnish men and women. Circ Heart Fail. 2011;4:607-12. https://www.ncbi.nlm.nih.gov/ pubmed/21914814.

35. McCullough ML, Patel AV, Kushi LH, Patel R, Willett WC, Doyle C, et al. Following cancer prevention guidelines reduces risk of cancer, cardiovascular disease, and all-cause mortality. Cancer Epidemiol Biomark Prev. 2011;20:1089-97 https://www.ncbi.nlm.nih.gov/pubmed/21467238.

36. McKenzie F, Ferrari P, Freisling $H$, Chajes V, Rinaldi S, De Batlle J, et al. Healthy lifestyle and risk of breast cancer among postmenopausal women in the European prospective investigation into Cancer and nutrition cohort study. Int J Cancer. 2015;136:2640-8. https://www.ncbi.nlm.nih.gov/ pubmed/25379993.

37. Vergnaud AC, Romaguera D, Peeters PH, Van Gils CH, Chan DSM, Romieu I, et al. Adherence to the World Cancer Research Fund/American Institute for Cancer Research guidelines and risk of death in Europe: results from the European prospective investigation into nutrition and Cancer cohort study1-5. Am J Clin Nutr. 2013;97:1107-20. https://www.ncbi.nlm.nih.gov/ pubmed/23553166.

38. Hulsegge G, van der Schouw YT, Daviglus ML, Smit HA, Verschuren WMM. Determinants of attaining and maintaining a low cardiovascular risk profile-the Doetinchem cohort study. Eur J Pub Health. 2016;26:135-40. https:// www.ncbi.nlm.nih.gov/pubmed/26130798.

39. Nomura SJO, Dash C, Rosenberg L, Yu J, Palmer JR, Adams-Campbell LL. Is adherence to diet, physical activity, and body weight cancer prevention recommendations associated with colorectal cancer incidence in African American women? Cancer Causes Control. 2016;27:869-79. https://www. ncbi.nlm.nih.gov/pubmed/27220873.

40. Knuiman MW, Divitini ML, Buzas JS, Fitzgerald PEB. Adjustment for regression dilution in epidemiological regression analyses. Ann Epidemiol. 1998;8:56-63.

41. Clarke R, Shipley M, Lewington S, Youngman L, Collins R, Marmot M, et al. Underestimation of risk associations due to regression dilution in long-term follow-up of prospective studies. Am J Epidemiol. 1999;150:341-53.

42. Silsbury Z, Goldsmith R, Rushton A. Systematic review of the measurement properties of self-report physical activity questionnaires in healthy adult populations. BMJ Open. 2015;5:e008430.

\section{Publisher's Note}

Springer Nature remains neutral with regard to jurisdictional claims in published maps and institutional affiliations. 